\title{
sala preta
}

ppgac

\section{A questão da soberania em África como uma peça teatral: modos destrutivos e criativos de se pensar ${ }^{1}$}

\section{The question of sovereignty in Africa as a theatrical play:destructive and creative ways of thinking}

\section{Luciano Mendes de Jesus Sayonara Pereira}

Luciano Mendes de Jesus

Doutorando em Artes Cênicas. Orientadora: professora Dra. Sayonara Pereira. Bolsista da Coordenação de Aperfeiçoamento de Pessoal de Nível Superior (Capes). Ator, diretor, músico, professor e pesquisador. Atuou no Workcenter of Jerzy Grotowski and Thomas Richards (Itália/2012-2015). Atualmente coordena a ação artística Ponte Elemento Per, desenvolvendo a Plataforma Garimpar em Minas Negras Cantos de Diamante

Sayonara Pereira

Professora efetiva da Escola de Comunicações e Artes da Universidade de São Paulo (ECA-USP). Estudou dança e atuou na Alemanha durante 19 anos (1985-2004). Pedagoga em Dança pela Hochschule Für

Musik und Tanz/Köln. Possui pós-doutorado (2009) em Dança pela Universidade Estadual de Campinas

(Unicamp). Aperfeiçoamento na Folkwang Hochschule - Essen (1985), dirigida por Pina Bausch. Autora do livro Rastros do Tanztheater no processo criativo de ESBOÇO (2010). Dirige o Laboratório de

Pesquisas e Estudos em Tanz Theatralidades (Lapett) no Campus de Artes Cênicas (CAC-ECA-USP)

1 Este trabalho foi realizado com apoio da Coordenação de Aperfeiçoamento de Pessoal de Nível Superior (Capes).

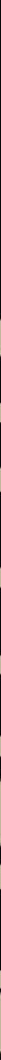




\section{Resumo}

Este artigo propõe a articulação de ideias no campo dos estudos das relações internacionais em África em diálogo com as possibilidades do teatro como um campo experimental de observação de fatos sociopolíticos, a partir da oposição entre a visão afrocentrada de Grovogui e a visão ocidental de Jackson sobre as construções sociopolíticas dos Estados e noções de soberania em África, tendo por base um fato histórico envolvendo a figura de Tierno Bokar, líder religioso islâmico do Mali. Partindo deste caso, reflito sobre como a figura histórica do líder malinês foi retratada em cena pelo griot e ator Sotigui Kouyaté (Mali/Burkina Faso), no espetáculo também intitulado Tierno Bokar, dirigido por Peter Brook, com atores de múltiplas nacionalidades do Centre International de Recherche Théâtrale (Cirt). Desta forma o grupo teatral é analisado como um laboratório para se pensar as relações internacionais num jogo transversal envolvendo cultura e política.

Palavras-chave: Relações Internacionais, Interculturalidade, Teatro Africano.

\section{Abstract}

This article proposes the articulation of ideas in the field of International Relations studies in Africa in dialogue with the possibilities of the theater as an experimental field of observation of sociopolitical facts, starting from the opposition between the Afro-centered vision of Grovogui and the western vision of Jackson on the socio-political constructions of states and notions of sovereignty in Africa, based on a historical fact involving the figure of Tierno Bokar, an islamic religious leader of Mali. Starting from this case, I reflect on how the historical figure of the Malian leader was portrayed on the stage by the griot and actor Sotigui Kouyaté, in the spectacle Tierno Bokar, directed by Peter Brook, with actors of multiple nationalities of the Centre International de Recherche Théâtrale (Cirt). Thus, the theater group is analyzed as a laboratory to think international relations in a transversal game involving culture and politics.

Keywords: International Relations, Interculturalism, African Theater. 


\section{Uma advertência}

É necessário, primeiramente, que eu evidencie o meu lugar de fala na escrita deste artigo.

Não posso falar do lugar de um estudioso, ainda que por vias indiretas ou paralelas, das questões das relações internacionais, especialmente aquelas que envolvem o diálogo politicamente tenso entre África e pensamento ocidental. Não domino, ainda que somente por agora no atual desenvolvimento da pesquisa que realizo sobre elementos de africanidades em cenas contemporâneas, as terminologias e as ferramentas de investigação e reflexão neste campo.

Meu lugar de fala é outro, transversal às questões estritas das expertises das relações internacionais. Por isso, o que posso fazer neste caso é, me utilizando de algumas ferramentas, terminologias e referenciais próprias da minha área de formação, as Artes Cênicas, estabelecer uma linha de conversa com as ricas e complexas temáticas com as quais me aproximei na minha busca por entender a África contemporânea, com idiossincrasias distintas da África antiga à qual minha pesquisa acadêmica tem me feito orbitar mais fixamente.

A aproximação por este novo viés, político ao invés de diretamente pelo campo artístico, deveu-se graças aos encontros com a professora Amy Niang, da University of the Witwatersrand (Johannesburgo/África do Sul), professora visitante no Instituto de Relações Internacionais da Universidade de São Paulo (IRI-USP), no segundo semestre de 2018, no qual realizei a disciplina Relações Internacionais em África.

A partir deste ponto de vista é que não corro tanto o risco de me perder num oceano de superficialidades, numa tentativa leviana de me apropriar de um campo de estudos ainda pouco conhecido por mim, no qual apenas algumas aulas não poderiam suprir a fundamental formação de anos. Assim, preciso me orientar por uma bússola que pode me levar a me aproximar das lógicas que envolvem as reflexões num campo fluido, como percebi ser o das relações entre África e Norte Global nos campos econômicos e políticos, mas que parte de direções mais condizentes com uma honestidade intelectual de minha parte, em respeito tanto à área de conhecimento e seus pesquisadores, quanto a mim, mesmo enquanto acadêmico em formação. 


\section{Um diálogo tenso}

A leitura inicial dos textos de Siba N'Zatioula Grovogui', "Regimes of sovereignty: international morality and the African condition"2 e de Robert Jackson", "Juridical Statehood in Sub-Saharan Africa", revelam imediatamente as experiências antagônicas que constituem a visão destes dois autores sobre a questão da formação dos modernos Estados africanos pós-coloniais e das soberanias nacionais. Não é absurdo considerar que o caráter experiencial - no sentido de uma percepção educada no contexto direto em que se vive - não afete estas visões.

Por isso, quando um estudioso africano como Grovogui, nato da Guiné Conacri, fala sobre África está trazendo não apenas uma reflexão pautada por observações estatísticas e considerações da reflexão política acadêmica, como o faz Jackson, canadense da Columbia Britânica, mas também por um estofo vivencial da condição de testemunha ocular e "vítima" dos acertos e erros das políticas africanas contemporâneas, afetadas pelas heranças coloniais, pelas lutas pós-coloniais e pelas reconstruções do afroperspectivismo decolonial.

É possível observar que no desenvolvimento do diálogo entre estas duas visões está presente a sombra daquilo que Achille $\mathrm{Mbembe}^{5}$ (1957) comenta como a tentativa ocidental de deslegitimar a África pensada por africanos:

There, in all its closed glory, is the prior discourse against which any comment by an African about Africa is deployed. There is the language that every comment by an African about Africa must endlessly eradicate, validate, or ignore, often to his/her cost, the ordeal whose erratic fulfillment many Africans have spent their lives trying to prevent. (MBEMBE, 2001, p. 5) ${ }^{6}$

1 Professor de Pensamento Político, Teoria e Legislação em Relações Internacionais e Estudos Africanos na Cornell University, em Ithaca, Nova York, EUA.

2 Regimes de soberania: moralidade internacional e condições africanas.

3 Professor de Ciência Política na University of British Columbia, Vancouver, Canadá.

4 Estado Jurídico na África Subsaariana.

5 Filósofo, teórico político, historiador, intelectual e professor universitário camaronês; escreveu obras de impacto no pensamento afrocentrado contemporâneo, como Crítica da razão negra (2014) e Políticas de inimizade (2017).

6 Lá, em toda a sua glória fechada, está o discurso anterior contra o qual qualquer comentário de um africano sobre a África é implantado. Há o discurso de que todo comentário de um africano/a sobre a África deve erradicar, validar ou ignorar incessantemente, muitas 
Tal postura que, em relação ao tema da discussão que os textos de ambos os autores promovem, se observa na incredulidade do Norte Global na capacidade da construção de Estados de Direito em África, assim como de soberanias plenas e em posição de negociação equânime com as grandes potências mundiais.

Para confirmar que não existe um modelo de governança mundial (em termos de Estado e soberania), ou melhor, que não existe somente um modelo de governança eurocêntrico herdado dos períodos coloniais em África, Grovogui indica que existe uma legitimação específica de meios de governança para cada país, que mantêm pontos de contato por similitude na rede global, mas que se organizam sob diferentes pressionamentos das relações históricas de poder locais. No entanto, a pasteurização por uma forma de governança de modelo europeu em África cria algo como "one regime [that] contributed to the 'resilience' of European 'quasi-states', another [that] helped to undermine the sovereignty of African entities and, later, to assist in the 'failure' of a number of African states" (GROVOGUI, 2002, p. 316)7.

A crítica de Grovogui ao modelo de pensamento defendido por Jackson se torna ainda mais direta e contundente ao citar o próprio autor como um exemplo de postura de análise da política internacional que relativiza o papel do Ocidente sobre a fragilização das estruturas internas de governança africana, ao mesmo tempo que defende o papel das nações "ex-colonialistas" como de fundamental importância para o cuidado com os cidadãos africanos e de proteção de liberdades individuais nos países afetados por uma soberania corroída por corrupções, guerras civis e instituições ineficientes. Poderíamos dizer que esta linha de pensamento de Jackson legitima a criação de "sobre-soberanias invisíveis", ou seja, a presença de uma governança não-oficial sobre os assuntos internos dos países africanos, como o foi com a influência subterrânea dos Estados Unidos durante o processo de golpe institucional no Brasil, que culminou com a eleição de um presidente predisposto à subalternização nacional diante do programa imperialista estadunidense.

vezes ao seu custo, a provação cujo cumprimento errático muitos africanos passaram a vida tentando evitar (tradução nossa)

7 'Um regime [que] contribuiu para a 'resiliência' dos 'quase-estados' europeus, outro [que] ajudou a minar a soberania das entidades africanas e, mais tarde, para ajudar no 'fracasso' de vários estados africanos" (tradução nossa). 
Jackson's moral theory is built upon two disjointed contentions. One is that political intolerance and economic mismanagement are endemic to the postcolonial condition because these states deviate from Western traditions of constitutionalism, political toleration and democratic pluralism. The other commonplace is that the ability of Western states to live up to Westphalian norms endows them with the capacity and wisdom to know the standards of conduct to which others must conform. These two assumptions lead Jackson to propose that Western states should take an active role in rethinking the 'right' ofpostcolonial states to 'non-intervention' The aim of Western intervention would be to protect the interests of the citizenries against tyrants, dictators and corrupt officials. (Ibid., p. 322) ${ }^{8}$

Buscarei demonstrar agora, através de um evento histórico bem localizado, como se dá uma forma de operação invasiva de um país colonial europeu sobre um assunto justificado pela noção westfaliana ${ }^{9}$ de soberania nacional, de maneira que comprova o que Grovogui argumenta como a união entre um ethos de hierarquia e privilégio e um mecanismo de subordinação e discriminação praticado em regimes de soberania instituídos pelas hegemonias modernas (Ibid.), e que Mbembe ratificará com a leitura da soberania como o exercício biopolítico sobre a dinâmica morte/vida e a materialização do poder.

\section{O caso de Tierno Bokar}

Tierno Bokar Saalif Tall (1875-1939) nasceu e viveu no Mali, que durante o período colonial também foi chamado de Sudão Francês. De formação muçulmana, filiava-se à corrente Sufi, braço místico do Islamismo, e é tido como um dos

8 "[...] A teoria moral de Jackson é construída sobre duas contendas desarticuladas. Uma é que a intolerância política e a má administração econômica são endêmicas da condição pós-colonial, porque esses estados se desviam das tradições ocidentais de constitucionalismo, tolerância política e pluralismo democrático. O outro lugar-comum é que a capacidade dos estados ocidentais de viver de acordo com as normas vestfalianas Ihes confere capacidade e sabedoria para conhecer os padrões de conduta aos quais os outros devem obedecer. Estas duas suposições levam Jackson a propor que os estados ocidentais devem ter um papel ativo em repensar o 'direito' de estados pós-coloniais à 'não-intervenção'. O objetivo da intervenção ocidental seria proteger os interesses dos cidadãos contra tiranos, ditadores e funcionários corruptos." (tradução nossa).

9 O sistema westfaliano, originário de uma série de tratados de paz entre nações europeias do século XVII ao XVIII, caracteriza a fundamentação dos estudos em Relações Internacionais, a partir do ponto em que esse sistema se pauta pela noção de estado-nação e seus elementos constituintes, como soberania nacional, equilíbrio de poder regional e definição de fronteiras. 
maiores mestres desta tradição na África. Sua biografia e seus ensinamentos são narrados por Amadou Hampâté Bâ no livro A spirit of tolerance: the inspiring life of Tierno Bokar (no original Vie et enseignement de Tierno Bokar) (BÂ, 2008).

A passagem de sua vida que exemplifica de forma contundente a relação conflituosa entre as noções de soberania, nas perspectivas de Grovogui e Jackson, está numa situação que envolveu a prática corânica da oração conhecida como Pérola da Perfeição, uma contenda na qual Tierno Bokar teve papel fundamental e que se desenrolou num quadro que envolveu política interna e externa, onde se viu com destaque o papel insidioso da França colonial.

A origem dessa contenda é a seguinte:

Cada manhã na zouïla, após a reza da aurora, os adeptos se reuniam diante do seu mestre para recitar as preces especiais, que sempre terminavam com a recitação da prece "A pérola da perfeição" 11 vezes. Ao final, o Cheikh tinha o costume de benzê-los dizendo a Fatiha. Um dia, porém, seus discípulos começaram a recitar sem a sua presença. Quando estavam prestes a terminar a 11프 repetição, o Cheikh chegou. Espontaneamente para não o constrangerem, os discípulos repetiram mais uma vez, completando assim 12 vezes. Logo em seguida, o Cheikh os benzeu com a Fatiha. No dia seguinte, ao chegar à $11^{\text {a }}$ repetição os discípulos olharam para o mestre. Como ele nada disse, repetiram mais uma vez. E assim se criou um novo costume que passou a ser seguido em vários lugares. (BERNAT, 2013, p. 102)

Deste incidente com ares cômicos outros fatos se desenrolaram, mas que não cabem aqui discorrer. $O$ fato é que se criou uma dissidência na comunidade islâmica africana, onde havia seguidores das 11 repetições, tido como puristas e tradicionalistas, e das 12 repetições, tidos como desvirtuadores dos aspectos místicos contidos no sentido do número de repetições originais. Desta divisão aproveitou-se o governo francês, interessado, através do apoio ao conflito civil, em manter seu domínio de raízes escondidas, em muito semelhante à estratégia lily-pad ${ }^{10}$ adotada pelos Estados Unidos na

10 "Unknown to most Americans, Washington's garrisoning of the planet is on the rise, thanks to a new generation of bases the military calls 'lily pads' (as in a frog jumping across a pond toward its prey). These are small, secretive, inaccessible facilities with limited numbers of troops, spartan amenities, and prepositioned weaponry and supplies." (VINE, 2017). "Desconhecida para a maioria dos estadunidenses, a guarnição do planeta por Washington está em ascensão, graças a uma nova geração de bases que os militares chamam de 'almofadas de lírio' (como um sapo que salta através de [nenúfares em] uma 
África atualmente. Os franceses apoiaram as 12 repetições como um exemplo de renovação dos costumes contra o atraso do desenvolvimento cultural africano, que estaria representado pela prática anterior. Nesse contexto surgiu o Cheikh Hamallah, cuja influência e partidarismo das 11 repetições eram muito expressivos, ao ponto de sofrer uma dura perseguição do governo colonial, com situações de tortura e deportação para a França, onde veio a falecer.

Em meio a esta situação surge Tierno Bokar, partidário das 12 repetições, mas não intolerante à prática original, que após encontros secretos com Hamallah, para entender seu ponto de vista, decide também por voltar a adotar a forma de oração tradicional. Esta mudança o fez ser julgado como traidor de sua linhagem, ligada ao líder do Império Tuculor, Alhaji Omar Tal, que seguia os renovadores da oração. Sendo também perseguido por opositores islâmicos e o governo francês, e passando por privações, morreu em Bandiagara.

Ao trazer de maneira extremamente sintética o caso desta oração e daqueles que nela tiveram participação, pretendo demonstrar como a noção de soberania em África segue caminhos complexos, que não podem caber numa lógica de soberania comum do Norte Global, como fica sugerido por Jackson, e ao mesmo tempo como a interferência colonial, com intenções de vantagens políticas e de economia estratégica, podem na verdade ser lidas sob uma ótica de soberania distinta. Uma perspectiva de soberania como ação criadora das políticas de inimizade e estado de exceção como Mbembe desenvolve em suas reflexões.

Na perspectiva aberta por Mbembe, a partir da qual a soberania é lida como o poder sobre a vida e a morte do outro, o caso da Pérola da Perfeição se torna modelar para ver o papel do Ocidente colonial como criador de "sobre-soberanias invisíveis." Cheikh Hamallah, Tierno Bokar e seus seguidores se tornaram as vítimas de um sistema duplo de aparelhagem estatal da morte.

Primeiramente porque foram colocados sob o julgamento de um governo local (do Mali) culturalmente organizado sobre pressupostos religiosos, sustentados por um sistema de leis pouco flexíveis e muito ortodoxas - ainda que a ortodoxia seja manipulável dentro de um sistema de interesses políticos

lagoa em direção a sua presa). Estas são instalações pequenas, secretas e inacessíveis, com um número limitado de tropas, amenidades espartanas e armamento e suprimentos pré-posicionados." (tradução nossa). 
movidos pelo estado de terror "refinado e sutil" promovido pela França. Em segundo lugar porque seus posicionamentos demonstraram ser corrosivos do status quo do tipo de governança colonial que a França imprimia sobre o Mali, que não apenas pelo pressionamento de um poderio militar maior, mas também por um processo de aculturação, consolidava um poder de decisão sobre as instituições tradicionais malinesas.

Entre estas duas forças, a da nação a qual pertenciam e a do estrangeiro colonialista, Hamallah e Bokar se tornaram presas de duas faces da soberania como política da morte. Por um lado, a soberania nacional que se ampara na renovação da tradição justificada pela linhagem do líder, por outro, a soberania do colonizador - com uma intervenção discreta, mas sólida e atenta às idiossincrassias culturais do povo malinês - que, em colaboração mútua com a governança interna, mantém firme uma rede de benefícios aos seus apoiadores. É desta dupla pressão que pode emergir o sentido de soberania proposto por Mbembe:

Formas de soberania cujo projeto central não é a luta pela autonomia, mas a "instrumentalização generalizada da existência humana e a destruição material de corpos humanos e populações." Tais formas da soberania estão longe de ser um pedaço de insanidade prodigiosa ou uma expressão de alguma ruptura entre os impulsos e interesses do corpo e da mente. De fato, tal como os campos da morte, são elas que constituem o nomos do espaço político em que ainda vivemos. (MBEMBE, 2018, p. 10-11)

Diante desta prática de soberania "estupradora" praticada e imposta pelos governos coloniais e imperialista sobre África é que a figura de Bokar, concedendo o seu apoio ao Cheikh Hamallah, faz emergir uma outra forma de soberania autêntica. Uma soberania realizada por um princípio de coerência com fundamentos da tradição da cultura sufista, que em certa medida ecoou no processo de independência do Mali, iniciado poucos anos após a morte de Bokar, através da percepção dos malineses de que era possível resistir ao domínio francês. Uma resistência inicialmente pacífica, resistência cultural, orientada pelos princípios de tolerância religiosa e política que o mestre sufi pregava, como Mahatma Gandhi operou na Índia.

E o que acontece quando o teatro, o "aparelho para ver", se torna uma ferramenta para a compreensão das dinâmicas das relações internacionais envolvidas neste caso? 


\section{O espetáculo como microcosmo das grandes relações internacionais}

Visualizando o antagonismo dos pensamentos de Grovogui e de Jackson, e percebendo a insídia francesa (mas que é válida como atitude comum a todos os países coloniais) sobre uma demanda cultural que ganhou dimensões políticas no Mali, depreendemos da colaboração destes fatores o aspecto de tensão dialógica que vai sempre estar presente ao se tratar o assunto das relações internacionais envolvendo África e o Norte Global.

Este jogo é dramático por excelência, quando compreendemos o drama como uma situação na qual se movem desejos opostos. Deste significado nasce a síntese de um modo de compreender a situação africana pós-colonial e na contemporaneidade. O jogo dramático no qual a África foi inserida pelo Ocidente a coloca como a protagonista mais vilipendiada de toda a História da humanidade.

É no espaço do teatro, com suas diversas e variáveis regras de atuação e delimitações espaciais e temporais, que podemos ter uma excelente ferramenta para se observar o conflito de soberanias. No espetáculo Tierno Bokar é possível ver, em níveis intensivos, a recriação de um campo de tensões entre África e Europa pela pura presença de atores africanos e europeus compartilhando o mesmo espaço cênico. Não digo de uma tensão pessoal entre os atores em si - o que de fato não posso afirmar que tenha ou não existido -, mas de uma tensão latente pelo elemento político trazido de forma inevitável por seus corpos e nacionalidades. A nacionalidade dos atores, especialmente quando representam nações com crises diplomáticas e dívidas históricas, são levadas em conta pela dramaturgia contemporânea, pois são aspectos informativos e de enunciação do conflito a ser lido na obra de arte.

Provocação semelhante se vê em situações de competição esportiva, como na Copa do Mundo de futebol de 2014, quando houve a iminência de uma partida de quartas-de-final entre Argélia e França.

Neste período eu estava trabalhando em Paris com a equipe do Open Program do Workcenter of Jerzy Grotowski and Thomas Richards. Estava hospedado em Montreil, região suburbana onde vivem grande número de imigrantes africanos islâmicos, especialmente do Mali e Argélia. Era a época do 
Ramadã também. Estava muito forte a atmosfera de uma vingança simbólica da Argélia em relação à França devido ao passado colonial. Mas nunca saberemos o resultado desse jogo de futebol, por não ter acontecido. A Argélia perdeu para a Alemanha nas oitavas de final.

De volta ao tema principal...

O griot e ator Sotigui Kouyaté ${ }^{11}$ interpreta Tierno Bokar e corporifica a própria história dos conflitos vividos pelo mestre sufi, uma vez que o próprio Sotigui é malinês de nascimento e cresceu sob a sombra dos ensinamentos de Bokar, que estiveram ao menos indiretamente ligados à sua formação corânica.

O conflito com a França colonial, através da peça, redimensiona a ideia sobre soberania para além dos aspectos geopolíticos e toca na noção biopolítica referida por Mbembe. $O$ corpo africano de um ator, que narra e revive uma opressão, serve de avatar para que possamos compreender que a máquina de morte que os regimes coloniais operaram sobre África (pela escravidão, guerras tribais, militarização, pelo combate ao terrorismo) quis construir um continente objetificado sobre o qual tivesse posse material. Paradoxalmente, é esta mesma presença de corpos africanos, que não revelam somente a negritude, mas também historicidade e cultura, que permite ver o deslocamento do Ocidente defrontado diante da complexidade dos sistemas tradicionais que organizam o modus operandi africano. O seu desarranjo diante disso revela o quão ridículos são os estrangeiros, essencialmente.

Diante da fragilidade revelada pelo patético de suas presenças no seio de outra cultura, tendem a responder reativamente (como o resultado de um choque cultural mal assimilado), o que, em nível sociopolítico macrocósmico das relações internacionais opressivas desenvolvidas pelas nações colonialistas-imperialistas, se expressa no poder sobre a vida e a morte. A violência contra a nação oprimida é a reação natural, uma vez que estarão expostos ao riso, caídos na lama do não-lugar. Como demonstrou Bergson nos estudos sobre o cômico, ao indicar a queda de alguém como disparador do riso de

11 Sotigui Kouyaté (Mali, 1936 - Paris 2010) foi griot e multiartista. Sua linhagem como griot remonta ao Império Mali, no século XI. Como artista trabalhou em teatro e cinema, consolidando uma trajetória mundialmente reconhecida, especialmente pela sua colaboração com o diretor inglês Peter Brook. Seu trabalho pode ser visto em filmes como O Mahabharata e Little Senegal. 
outro "ri-se porque a pessoa sentou-se sem querer. Não é, pois, a mudança brusca de atitude o que causa riso, mas o que há de involuntário na mudança, é o desajeitamento." (BERGSON, 1983).

Os franceses encontram resposta à sua ridicularização pelo fomento e realização de opressão sobre lideranças africanas legítimas e legitimadas pelo povo malinês e de outras áreas subsaarianas. Este ridículo da atitude colonial francesa no Mali é retratado em dois momentos no espetáculo:

Um comandante francês [...] obriga um grupo de rapazes africanos a pavimentar uma estrada toda enlameada e acaba se afogando no barro. O caráter patético desta situação revela muito mais sobre as injustiças e a arbitrariedade do que qualquer discurso político. [...] A cena em que um grupo de meninos negros descobre que as fezes dos colonizadores brancos também são escuras e cheiram mal mostra como é absurda a desigualdade entre homens a partir da simplicidade presente na percepção infantil. (BERNAT, 2013, p. 106)

A questão do diálogo entre atores estrangeiros, em cena, abre uma via de pensamento provocativa sobre como entender as relações internacionais entre Norte e Sul Global a partir de uma experiência prática de encontro humano, que se dá através do teatro. Isto porque o espetáculo, pelo aspecto visual-narrativo, estabelece um distanciamento para aquele que observa os acontecimentos, podendo este refletir sobre os eventos sociopolíticos com certa flexibilização de posicionamento ideológico anterior - uma vez que a obra Tierno Bokar utiliza o elemento político inerente ao tema para extrapolá-lo em direção à compreensão dos ensinamentos de Bokar sobre tolerância e não-violência.

Longe de apelar para uma resolução simplista de conflitos e harmonia de interesses isenta de tensões, inclusive considerando a violência como um fator de impulso primordial das situações da biopolítica da soberania nos últimos dois séculos de história do continente africano, podemos perceber o caminho discursivo de Cheikh Hamallah, Tierno Bokar e da trupe pluriétnica do Centre International de Recherche Théâtrale (Cirt) de Peter Brook ${ }^{12}$ como

12 Peter Brook (1925) é diretor de teatro, ópera e cinema, além de escritor. Após dirigir a Royal Shakespeare Company empreende, a partir dos anos de 1970, uma busca por um teatro intercultural como uma forma de conhecimento do ser humano e de renovação criativa, levando-o à criação do Cirt. As experiências em África e Oriente Médio foram determinantes para a sua produção artística, que influenciou profundamente a cena tea- 
respostas humanitárias para o desafio do desenvolvimento de relações internacionais com potência criativa, que problematiza o choque cultural para além de regimes econômicos e geopolíticos, e o aborda no campo da diversidade de subjetividades dos atores sociais envolvidos.

\section{Conclusão}

A construção das diversas soberanias das nações africanas, desembaraçadas dos laços que foram colocados nelas pelos países coloniais-imperialistas, é um processo contínuo, de longa duração, pois que, após o vilipêndio das instituições autônomas, da fragmentação de sistemas culturais e fomento aos conflitos civis promovidos pelo Ocidente, o que existe é uma busca da superação da africanização, da África pela própria África.

Uma africanização que pode ser compreendida quando Jackson postula que

The independence and survival of African states is not in jeopardy because their sovereignty is not contingent on their credibility as authoritative and capable political organizations. Instead, it is guaranteed by the international community, especially as embodied in the United Nations. $\left(\right.$ JACKSON, 1992, p. 2) ${ }^{13}$

Assim, com o discurso da subalternidade de uma África sempre infantilizada ao longo do século XX, hoje, com a sombra fantasmagórica de uma tutela indefinidamente duradoura até seus habitantes serem capazes de suportar "as extenuantes condições do mundo moderno" (Ibid., p. 3), os interesses de países de passado colonial como França e Inglaterra, e de países imperialistas como os Estados Unidos, operam seus programas de soberania imposta pela força e pelo terror.

O espaço de respiro que a África encontrou e ainda encontra diante destes programas pode se dar pela resposta violenta e extremista, mas também

tral contemporânea, ainda que suas práticas sejam alvo de críticas para pesquisadores decoloniais, como Rustom Barucha (1953).

13 "A independência e a sobrevivência dos estados africanos não estão em perigo porque sua soberania não depende de sua credibilidade como organizações políticas competentes e capazes. Em vez disso, é garantido pela comunidade internacional, especialmente conforme incorporado nas Nações Unidas." (tradução nossa). 
pode se dar pela cultura de paz fomentada por pessoas como Tierno Bokar, que também consiste em uma forma de criação de soberania, amparada numa outra biopolítica, expressa na presentificação de um corpo com história, que resiste acreditando na pluralidade de outros corpos com história coexistindo e não sobrepondo-se uns aos outros.

Corpos com história sendo armas não-letais, porém de existência plena e radical.

Coexistência que Bokar sintetiza na máxima: "Existem três verdades: a minha verdade, a sua verdade e a Verdade" (BERNAT, 2013, p. 110).

Presença, ética e palavras-força que Sotigui Kouyaté aprendeu em sua formação corânica e de griot, e que sempre as expressava em suas palestras, oficinas e obras artísticas, ainda que permanecesse em absoluto silêncio.

\section{Referências bibliográficas}

BÂ, A. H. A spirit of tolerance: the inspiring life of Tierno Bokar. Bloomington: World Wisdom, 2008.

BERGSON, H. O riso: ensaio sobre a significação do cômico. Rio de Janeiro: Zahar, 1983.

BERNAT, I. Encontros com o griot Sotigui Kouyaté. Rio de Janeiro: Pallas, 2013. GROVOGUI, S. N. Z. Regimes of sovereignty: international morality and the African condition. European Journal of International Relations, Thousand Oaks, v. 8, n. 3, p. 315-338, 2002. DOI: https://doi.org/10.1177/1354066102008003001 JACKSON, R. Juridical statehood in Sub-Saharan Africa. Journal of International Affairs, Hanover, v. 46, n. 1, p. 1-16, 1992.

MBEMBE, A. Necropolítica: biopoder, soberania, estado de exceção, política da morte. São Paulo: N-1, 2018.

MBEMBE, A. On the postcolony. Berkeley: University of California Press, 2001.

VINE, D. The lily-pad strategy: how the Pentagon is quietly transforming its overseas base empire. Huffpost, [S. I.], 16 jul. 2012. Disponível em: https://bit.ly/2ZKAC4S. Acesso em: 17 dez. 2018.

Recebido em 31/03/2019

Aprovado em 26/06/2019

Publicado em 30/08/2019 